\title{
Inclusion and Independence: The impact of Mobile Technology on the Lives of Persons with Disabilities in Kenya and Bangladesh
}

\author{
Nusrat Jahan \\ Global Disability Innovation \\ Hub. \\ University College London \\ London, Uk \\ j.nusrat@ucl.ac.uk \\ Naemur Rahman \\ Priti \\ Research and Consultancy Services \\ Dhaka, Bangladesh \\ naemur@pritibd.com
}

Giulia Barbareschi

University College London

Interaction Centre

University College London

London, Uk

giulia.barbareschi.14@ucl.ac.uk

\author{
Victoria Austin \\ Global Disability Innovation Hub. \\ University College London \\ London, Uk \\ victoria.austin@ucl.ac.uk
}

\author{
Clara Aranda Jan \\ Mobile for Development \\ GSMA \\ London, UK \\ carandajan@gsma.com
}

\author{
Charles Musungu Mutuku \\ Association for the Physically \\ Disabled of Kenya \\ Nairobi, Kenya \\ apdkmks@yahoo.com
}

\begin{abstract}
Globally, mobile technology plays a significant role connecting and supporting people with disabilities. However, there has been limited research focused on understanding the impact of mobile technology in the lives of persons with disabilities in low or middle- income countries. This paper presents the findings of a participatory photovoice study looking at the role that mobile phones play in the daily lives of 16 persons with disabilities in Kenya and Bangladesh. Participants used a combination of pictures and voice recordings to capture their own stories and illustrate the impact that mobile phone use has on their lives. Through thematic analysis, we categorized the benefits of mobile phones captured by participants as 1) Improved social connection; 2) Increased independence and 3) Access to opportunities. While mobile phones are ubiquitously used for communication, for persons with disabilities they become essential assistive technologies that bridge barriers to opportunities which are not accessible otherwise. Our paper adds evidence to the need for mobile phones for persons with disabilities to enable communication and connectivity in support of development.
\end{abstract}

Keywords-Mobile Technology, Disability, Kenya, Bangladesh, Social connection, independence, education, livelihoods

\section{INTRODUCTION}

Worldwide it is estimated that there are over a billion people who live with some form of disability [1]. Approximately $80 \%$ of people with disabilities live in low-and-middle income countries (LMICs). The combination of an inaccessible environment compounded by socio-economic factors such as poverty and stigma, makes it more likely for people with disabilities to be marginalised and excluded from society [1]. Assistive Technologies (ATs) are known to bridge the accessibility gaps and allow for greater social inclusion. However, there is a lack of adequate access to ATs in LMICs, combined with often poorly designed services, which only magnifies these challenges, thus limiting the opportunities for persons with disabilities to live an independent life [2]. Despite the importance of AT, access to AT globally is inadequate with only 10 percent of those in need having access to the ATs that they need [2].
Mobile phones and services have unparalleled reach globally with over 67 percent of the world's population (5.2 billion people) owning a mobile phone and 49\% (3.8 billion people) using mobile phone internet services; both figures are expected to rise to $70 \%$ and $61 \%$ respectively by 2025 with growth being driven by LMICs [3]. These devices have and will continue to transform the way societies communicate and interact. Although the primary purpose of a mobile phone is not to support independence and promote the wellbeing of persons with disabilities, they serve this purpose both through mainstream built in features and specifically designed apps and services [4]. A study of 150 experts across 55 countries ranked the internet and mobile phone devices and services as the most important technologies to drive the social and economic inclusion of persons with disabilities [5]. In addition, by using widely available software mobile phones offer a great opportunity for people with disabilities to be included in the mainstream of digital society. In turn helping to reduce stigma associated with traditional assistive technologies, reducing cost by including many assistive features as standard, and providing support for multiple impairments and requirements in one device [5]-[7].

While there is growing recognition that mobile technology has the potential to deliver services, improve social inclusion and civic participation of persons with disabilities, there has been limited research to understand: 1) how people with disabilities in LMICs access mobile phones, and 2) how does this access impact their everyday lives. The GSMA, a trade association representing mobile operators and digital players in the mobile industry globally, conducted a study in Kenya and Bangladesh showing that while many persons with disabilities own a mobile phone ( $82 \%$ in Kenya and $62 \%$ in Bangladesh) they are still over $10 \%$ less likely to own a mobile phone compared to people without disabilities [8]. Furthermore, people with disabilities were more likely to own a basic or feature handset as opposed to a smartphone [8]. Even when they owned a mobile phone, most people with disabilities still face several barriers using their devices due to issues related to cost of services, lack of accessibility features, low digital literacy and incorrect 
perceptions regarding usefulness of various mobile phone services [8]. Interestingly, people with disabilities in both countries reported that mobile phones enabled them to have better access to essential services such as healthcare, education and employment. This is despite their overall perception that access to services was limited for persons with disabilities [8].

Although people reported the usefulness of mobile phone for service access, it is unclear exactly how mobile phone helps. Understanding the how can better help to identify and remove barriers whilst simultaneously designing better mobile phone services across policies, provision systems, products and services.

Participatory methods are essential when working with people with disabilities and should be incorporated throughout the design phases to ensure users voices are heard [9]. Here we focus on the initial phases of conceptualization and design.

\section{METHODOLOGY}

This study aims to better understand the role of mobile phones as enablers of participation for persons with disabilities. The research follows an ethnographic qualitative approach called photovoice. Photovoice aims to engage members of marginalized communities as agents in the research, breaking down the barriers between researchers and participants [10]. The photovoice approach enables participants to share meaningful stories with the researchers in a way that feels natural to them [10].

The use of visual and audio materials as data, the involvement of participants as researchers and the possibility to conduct the research with people rather on people, make photovoice a research approach that is both inclusive and effective for engaging with people with disabilities [11]. By following this approach, our research seeks to align with the message from Disability advocates and the Disability Movement of "nothing about us without us" [12].

The study took place in Dhaka, Bangladesh and Machakos, Kenya between July and August 2019. Sixteen participants, 8 participants from each country, were recruited through local Community Based Organizations (CBOs) representing the interests of people with disabilities. A balanced representation of persons with different disabilities was sought based on type of disability (visual, hearing, speech, physical and other impairments), gender and age (from 18 to 65 years old) across three environments (informal, urban and rural). Once contacted, participants were invited to take part in the photovoice diary study for a period of 5 days. Table 1 shows the characteristics of the participants.

In each country, an initial training and sensitization workshop was held with all participants as a group to explain the focus of the research and to provide, where needed, cameras or audio recording devices (used by people with visual impairment). Some people opted to use their own mobile phones rather than a bespoke device. It also gave an opportunity to make sure people fully understood how to use the cameras appropriately. Participants collected data with the cameras for three days. Support was provided during this by two visits to each participant throughout the week of fieldwork by the first author and local research assistants (authors CMM and NR). Training materials, consent forms and other relevant documents were translated into local languages and sign language translators and carers were involved where necessary.

After data collection, one to one discussion and analysis of photos and recordings took place between the researcher and participant individually. A convenient location was agreed with the participant that safeguarded both parties. Audio recordings made by participants and final interviews with the participants were transcribed and translated into English where necessary. Data from pictures and transcripts were triangulated and analysed using thematic analysis [13].

TABLE I. CHARACTERISTICS OF PARTICIPANTS

\begin{tabular}{|l|l|l|l|l|l|}
\hline $\begin{array}{l}\text { Ref } \\
\text { Code }\end{array}$ & Country & Gender & Age & $\begin{array}{l}\text { Living } \\
\text { Environment }\end{array}$ & $\begin{array}{l}\text { Type of } \\
\text { Impairment }\end{array}$ \\
\hline BD01 & Bangladesh & Female & 18 & Slum & Speech \\
\hline BD02 & Bangladesh & Male & 46 & Urban & Visual \\
\hline BD03 & Bangladesh & Male & 22 & Rural & Physical \\
\hline BD04 & Bangladesh & Female & 40 & Urban & Physical \\
\hline BD05 & Bangladesh & Female & 30 & Slum & Visual \\
\hline BD06 & Bangladesh & Male & 25 & Rural & Speech \\
\hline BD07 & Bangladesh & Female & 46 & Rural & Hearing \\
\hline BD08 & Bangladesh & Female & 34 & Urban & Other \\
\hline KEN01 & Kenya & Male & 49 & Rural & Physical \\
\hline KEN02 & Kenya & Male & 34 & Urban & Other \\
\hline KEN03 & Kenya & Female & 30 & Urban & Hearing \\
\hline KEN04 & Kenya & Male & 34 & Urban & Hearing \\
\hline KEN05 & Kenya & Female & 40 & Slum & Physical \\
\hline KEN06 & Kenya & Male & 25 & Rural & Visual \\
\hline KEN07 & Kenya & Female & 49 & Rural & Visual \\
\hline KEN08 & Kenya & Male & 65 & Rural & Physical \\
\hline
\end{tabular}

\section{FINDINGS}

Through this research, participants captured images showing how persons with disabilities use mobile phone and services in their daily life. The use of mobile varied based on factors including social and economic context, education, types of disability, accessibility to and affordability of mobile phones and services. While stories in this research focused on the enabling role of mobile, persons with disabilities reported significant barriers to inclusion such as social isolation and discrimination, dependency on family and carers due to poor infrastructure, lack of access to services, and exclusion from education and livelihood opportunities. The value of mobile phones and devices is epitomised in the following responses from participants.

"For many of you mobile phone is just like any other device - for me it is a companion in my life." (KEN06, male, visual impairment)

"My disability is not that severe but in my support group there are people who don't go out much and mostly live an isolated life. Mobile phones always help them to be connected with the rest of the world. Also, it helps them to be engaged and 
not feel lonely. I consider my mobile phone as my companion." (BD03, male, physical impairment)

Mobile phones and services play a significant role in breaking social isolation and reducing loneliness through calling or messaging friends, family and support networks. Even access to the most basic mobile phone helped to improve the quality of life of persons with disabilities. These findings are grouped under support groups, family and friends and entertainment.

Based on the stories shared, the benefits can be categorised into three key areas A) Improved social connection; B) Increased independence and C) Access to opportunities.

\section{A. Improved social connection}

Where smartphones are accessible, connectedness to support groups, such as Disabled Persons Organizations (DPOs) and informal networks improves significantly, this gives people a sense of being connected to the broader society, as descried here:

"As a visually impaired person my mind is always active, I can't be distracted with visual things. Most of the time I like my mind to be engaged and my mobile phone gives me that opportunity. It brings joy to my life. It also helps me not to be isolated and to become more connected with the broader society." (KEN06, male, visual impairment)

One of the benefits of improved social connections particularly relevant to persons with disabilities is that participants were able to connect with others who face similar challenges and have found specific relevant solutions and opportunities in relation to their disability. Several noted that they had not had the opportunity to meet others with the same disability or even connect with some of their own extended family members before they had access to mobile phones and services. All of this helps to reduce loneliness and isolation and several participants even met their life partners through mobile phone enabled social connections.

\section{1) Support groups}

An example of the value of access to social networks through smartphone Apps such as WhatsApp is a 49 years old male participant from Kenya who has a physical impairment (KEN01). He uses his mobile phone to connect with ten different support groups. One of those is a volleyball group for persons with disabilities where he meets the members weekly to play volleyball and discuss other practical issues. He expressed how this gives him a sense of living a more independent life regardless of his disability. As he lives in a remote rural area this is essential for him to stay connected and is complemented by access to safer transport though known providers. BD03 also expressed the value of mobile phone to access support groups in terms of practical support and reducing loneliness:

"I am involved with many support groups. One group in Facebook I find very useful is the Promotion of Human Rights of Persons with Disabilities in Bangladesh (PHRPBD). In that group nine organizations are connected who are working on disability related issues. We regularly share our work / updates, have discussion and receive mutual learning from each other. It is a Facebook messenger group." (BD03, male, physical disability)
Conversely, the lack of mobile phone seems to magnify the social exclusion experienced by persons with disabilities. BD01, who has a speech impairment, finds it difficult to communicate when she is outside of the house. She was the only participant who did not own a mobile phone and due to her impairment, combined with a lack of sign language knowledge her brother answered on her behalf to many of the questions, on her behalf he stated:

"We didn't give any mobile phone to her because they are new in Gazipur Tongi. Most of the time she stays at home. She can use her husband's phone or my phone" [Brother of BD01].

2) Family and friends

"My mobile phone empowers me socially" [KEN08] was a statement we heard often. The value placed upon mobile phones by participants as a means of breaking social isolation and connecting with family and friends cannot be overstated. Many participants lived alone, and the mobile phone acted as a means to overcome loneliness, for example BD04, "Now I don't have to visit my village so frequently as I can talk with them and see them regularly through camera. I don't feel that much homesickness." (BD04, female, physical impairment). KEN08 found his "mobile phone holds the whole world together."

In some cases such as BD08, a Bangladeshi female with muscular dystrophy, the first contact with some relatives was facilitated by mobile phone and in others such as KEN08, a Kenyan male with a physical impairment, regular daily communication with relatives in Kenya and around the world was made possible by mobile phone. For BD08 for example, she is now "in touch with my family, relatives and friends and work contacts always communicate with me via my mobile phone." However, prior to having a mobile phone she was excluded form family communications and, in some cases, unknown to people. Through communication with the phone her world was opened up as it were, she said:

"Many of my cousins don't know about me and had never talked before, as I was not taken to social events. When they connect with Facebook they started contacting me in my mobile phone. Slowly I start attending social events like weddings, birthdays or other invitations after knowing them bit more. It gave me more confidence to attend as the start to counting me in the family." (BD08, female, muscular dystrophy)

However, connecting comes at a cost - affordable and suitable speed internet was a common challenge. KEN03 and KEN04 are married and both have hearing impairments. Video calling is the primary form of communication with their families, social and work networks. But KEN04 has connectivity issues ("The network is also a problem in our house as it is a hilly area."). BD04 has a physical impairment and lives independently in Dhaka city. She uses video calls to connect with family which reduces he sense of loneliness and isolation. This also has practical and financial benefits reducing the cost and challenges of visiting family on a regular basis. For other people, like those with speech and hearing impairments or sign language users, video calls supports non-verbal communication that other phones did not allow before.

\section{3) Entertainment}


There were also examples given by participants of using mobile phones for entertainment such as games, watching news, movies or videos on YouTube, finding recipes, reading online contents, and listening to music and talk-shows.

"I do online shopping regularly especially clothing...I use Imo and Facebook messenger. I also regularly use YouTube for my entertainment...I read online newspapers daily....If there is a new release of movie or drama I enjoy watching them on YouTube on my mobile phone. I also like old movie songs. I watch news mostly on my mobile phone instead of television." (BD04, female, physical impairment)

"I am a big fan of radio, music and also football. Mobile phone allows me to listen to my favourite music or get an update about my favourite player. I also use mobile phone internet for my own personal research related to my impairment or reading newspaper. It is a great help as the phone reads for me. Even though I can't see but I feel connected to the world. I could feel lost if I didn't have those entities in my life." (KEN06, male, visual impairment)

Many participants mentioned how they enjoyed online shopping including some international reach. For example, BD03 states: "There are online shopping pages such as 'shopno' and 'Brothers'. I enjoy shopping mainly for my clothing from there. It saves my time going to the shopping centre". The main benefit was not having to physically attend the shops where access is challenging. People often looked for assistive products using their mobile phone device, for example:

"Sometimes I go to the website of RNIB [Royal National Institute for the Blind] to find the latest assistive devices that are available. I ordered two white canes from their website which they sent by courier service." (BD02, male, visual impairment).

\section{$B$. Increased independence}

Mobile phones and services were perceived to have made a significant contribution to increasing independence. Many participants enjoy outdoors activities for work and social purposes without letting their disability restrict them. Mobile phones also improved a sense of safety, facilitated financial independence through reducing reliance on others for mobile phone money services and improving access to basic healthcare services.

A 40-year-old female participant (BD04) who has a physical impairment lives alone in Dhaka city, which is not very common in Bangladeshi culture. It is unusual for unmarried woman to live alone without a family member especially if they have a disability. The participant considers her mobile phone as a key support for her independent life.

"I consider my mobile phone as a companion in life. It is very important for me because I live alone, and a big part of my life depends on mobile phone services." (BD04, female, physical impairment).

Having access to the mobile phone and in particular topping up the credit of the phone was one of the few occasions BD01 left her home and appeared a significant event to her as evidenced by her photographing the event as part of her photovoice photos.

\section{1) Transport}

Mobile phones and services significantly improve accessibility of transport partly due to physical access and partly due to improved safety and trust. This in turn supports improved reliability and increased independence for persons with disabilities as well as social, educational and work-related opportunities. In both countries widely used types of transport included community or work contacts for rickshaws, motorbikes and tuk-tuks and online services such as 'Uber' and 'Pathao'. Several participants mentioned that they prefer to travel with the drivers they know for security. The most common arrangement is to call the driver in advance to schedule travel or in the case of emergency.

"I regularly depend on my mobile phone for my transport arrangements. I call a 'tuk-tuk' man or our office driver. When I call them they collect me from different places. One day it happened I had to come so late at night from Nairobi due to work. The vehicle broke down in the middle of the road. I got help through my mobile phone and got back safely. Another day I broke my crutches, but I had a spare at home, so I call and arranged for someone to pick up the crutches for me. Without my mobile phone my life will be very hard" (KEN05, female, physical impairment).

KEN01 is a confident, responsible and well-respected person among his peers and family. He uses a motorbike taxi everyday from a hilly area to reach his work. "Because of my mobile phone I am not isolated. If I need help for transport or other errands, I call someone and get support. You can see my workplace is a little distant from my residence. Usually I call them and check on them." (KEN01, male, physical impairment).

\section{2) Safety}

Participants felt safer with access to mobile phones and services in a range of contexts including transport as shown above but also access to other services and support structures such as the police or healthcare providers as well as family and friends.

BD04 stated she felt safer having access to a mobile phone in case of any health problem or criminal threat or incident. This is relevant both at home and going to and from work. BD04 also relies upon her mobile phone to stay connected to family reducing the cost and risk of travel so frequently to visit family and reducing social isolation.

"Even I am living alone but I feel safe, as I am able to seek assistance anytime. Mobile phone is supporting me to live my life independently." (BD04, female, physical impairment)

"As a disabled person, I feel it is very important for us to use mobile phones. We face lots of struggle and harassments in our day-to-day life. For example, if there is a near-by police station which we can be locate by Google Maps and seek support easily." (BD03, male, physical disability)

\section{3) Financial services}

The majority of photovoice participants use mobile financial services, such as mobile money (MPESA in Kenya and bKash in Bangladesh), giving them more independence, reducing transaction costs such as transport and improving access to services. Among the most important elements was not having to 
travel to access banks and being able to access information and services remotely. People specifically mentioned the use of money transfer and topping up mobile phone credit.

People had adapted the accessibility of the mobile phone to form a type of supported interaction. In this way, independence is gained, whilst still needing assistance. For example, KEN07 draws on the support of relatives ("When there is someone in the house, I check the balance in my MPESA account") but also keeps her pin number secret ("I put the number secretly which doesn't appear instead it appears as stars. If accepted, then it will show the person who will tell me how much is in my account"). She previously used a smartphone but now uses a basic button phone for ease of use after her sight deteriorated. With this phone she can access many MPESA services - "I also do shopping by MPESA. I also send and receive money."

Others including BD05 and BD03 used mobile phone financial services for day-to-day transactions. For example, BD03 found it essential for his work, he explains "Suppose I am working in the field and I am short of money then I call my office and they are always able to transfer the money into my account. It is a very easy and simple process."

Mobile phone money was also useful in emergencies. BD05, a Bangladeshi female with a visual impairment, explains:

"In an emergency bKash works well, for example when my mother in-law died, I needed money for the transport arrangement, so I informed my sister and she sent me 2,000 Taka immediately. It was very useful on that day."

It is clear that without mobile phone money people could have been stranded for example BD05 continues to explain: "If I didn't have bKash, then I might have to request a loan from other people, or they might not even offer me the money.".

4) Healthcare

Many of the photovoice participants used their mobile phones to access healthcare including booking appointments through calls and text messages as well as phone consultations.

KEN01 explains how his details are now "registered for medication and medical checks", which was completed via mobile phones. He explains "My insurance is also covered through mobile phone." Mobile phone was used by both KEN01 and BD03 for booking medical appointments. KEN01 explained sometimes he simply exchanged information with his doctor via text and voice calls, and not needing to travel:

"Sometimes, I just send a text and call to consult with my doctor directly to avoid a visit if it is not too serious. Since travelling takes out energy for me." (KEN01, male, physical impairment)

\section{Access to opportunities}

Participants stated that mobile phones and mobile phone services helped them to gain better access to education and livelihood opportunities. It is worth noticing that access to mobile phone internet was crucial to allow participants to leverage mobile phone features and services which they deemed most useful.
For some participants access to mobile phones and services enabled them to continue education, including distance learning, online research, higher education and professional development. Mobile phones also allowed some participants to become members of professional networks that they could leverage in their work. For example, KEN02, who has both a physical and a communication impairment as a result of Cerebral Palsy, reported that his mobile phone was instrumental to his ability to complete education and obtain a job in the local Governor's Office.

"I pursue my distance learning in leadership through the support of my mobile phone. I always use my mobile phone to access my email for assignments and notes. I also do online research through Google to complete my assignments. I frequently use WhatsApp for my work coordination purposes with the Nairobi office. My job fully depends on my mobile phone. Without a phone I would not able to perform my job." (KEN02, male, Cerebral Palsy/multiple impairments).

Similarly, BD02, who has a visual impairment and is a teacher at a local school for visually impaired persons, values the ability to access research online and download books though his mobile phone. Interestingly, he stated that audio content is both more convenient and accessible than braille. He uses a feature phone with internet access to download and listen to articles and other information in English as Bengali language not supported by his screen reader.

"I use my mobile phone for downloading and listening to books in my memory card. As I am a teacher it also helps me with the lesson preparation as I find reading in braille could be time taking but listening in mobile is a quicker option." (BD02, male, visual impairment).

\section{2) Livelihood}

Other participants reported that mobile phones are essential tools for their occupations. For example, KEN01, a man with a physical impairment who runs two small businesses both as a cobbler and selling water and oil, leverages a series of different mobile phone financial services to support his activities. The ability to access bank loans, pay suppliers and receive payment from customers through his mobile phone are crucial for him to be able to run his businesses more efficiently and independently.

"I regularly contact with my staff through mobile phone. We also have some loan facilities in KCB (Kenyan Commercial Bank). Online you can apply and take some loan and return with some interest monthly. I regularly take that loan and return them on time. The whole process I operate through mobile phone. I cannot do anything without a mobile phone. All my business correspondence depends on mobile phone." (KEN01, male, physical impairment)

Access to a mobile phone and other services such as mobile phone internet and social media enabled BD08 to co-found a Disabled People's Organisation (DPO) in Bangladesh in 2009. Thanks to her activity as a blogger she has also been awarded an international prize. Every day she uses her mobile phone to interact with her co-founder and, regardless of her physical impairment she has been able to leverage social media to 
establish, grow and mobilise a network of over 4000 people with disabilities in Bangladesh.

"Mobile phone and Internet was my very first step to get freedom and take control over my life. With the help of the mobile phone and internet use I managed to start writing online blogs, electronic media and platform like Facebook. By taking the advantage of mobile phone and Internet I organized many social events even though I have challenge with my mobility... Disabled persons can be more independent with support of mobile phone services. I can consider to skip a meal but not having a mobile phone any moment." (BD08, female, physical impairment)

Mobile phones allow people to communicate in different forms, not only by voice, but also via text or sign language. The availability of multi-modal forms of communication was crucial for KEN03 who worked as a tailor and has a hearing impairment. Her mobile phone enables her to communicate with her customers via text or video calls and to find inspirations for her creations.

"I am a tailor by profession. Sometimes I use the mobile phone internet to find designs from websites. I also contact my customers through mobile phone text. When the customer has chosen the design from the website then they agree about the price, materials and delivery dates. Customers communicate with me through text messages and sometimes using sign language in video calls" (KEN03, female, hearing impairment).

The high penetration of mobile phones also allowed BD03 who worked as a community mobiliser for an organization supporting the rights of people with disabilities to reach out to beneficiaries that would otherwise be left out, potentially compromising their abilities to engage in active citizenship.

"In my work as a community mobiliser I have to communicate with all the beneficiaries regularly through my mobile phone. Some members in the community have hearing impairments so I use video calls to use sign language to talk to them. There is no other alternative than mobile phone to contact them. It is very convenient and easy." (BD03, male, physical impairment).

Mobile phones were described as indispensable to support livelihood for participants who lived in rural areas, where the availability of in-person services was more limited than in urban areas. For example, KEN08 a Kenyan farmer with a physical impairment, relies on his mobile phone to contact veterinary services if his livestock are ill. Veterinary services are not widely available in his area and his mobile phone allows him to receive assistance at the first sign of any problem, protecting his cattle and his livelihood more effectively.

"When I am in need of a doctor for my cattle's I just call. Every morning I check all my cattle and there is something not right with their health I use the phone to call doctor immediately." (KEN08, male, physical impairment)

\section{DISCUSSION}

The stories collected by participants as part of this photovoice study show the significant advantages associated with access to appropriate mobile phones in the everyday lives of people with disabilities in Kenya and Bangladesh. In general, regardless of their gender, geographical location and type of disability, all participants who had access to mobile phones, have improved social connection, independence and access to opportunities. The benefits reported increased further when mobile phones which had internet access and smartphones that offered applications for messaging, social media or transport.

However, it is important to note that access to basic or feature phones was perceived as highly valuable by participants due to accessibility features, size, weight and functionality. In several cases participants chose to use basic or feature phones due to their specific needs as well as affordability. This is in line with results reported by [14] which showed that people with visual impairment who lived in a Kenyan informal settlement felt more independent using basic and feature phones compared to smartphones due to low levels of digital literacies and the difficulty encountered interacting with touch screen interfaces.

In terms of social connection mobile phones helped to break isolation enabling participants to feel and be better connected with friends, family and support groups through phone calls, text messaging and video calling applications. Video calls were particularly beneficial to those with speech and hearing impairments. However, video calls required participants to have access to smartphones and to be able to rely on stable and affordable internet connections which could represent a significant challenge, especially in rural areas [15].

Another aspect of social connection was through news, media and entertainment from radio and faith-based programmes to YouTube, social media and online games. All of these aspects help to reduce barriers and isolation of persons with disabilities and give them access to the outside world in situations where they may otherwise become isolated.

\section{A. Social connection}

The improved social connection demonstrated by this research is in line with other evidence that mobile phone devices can improve access to information, promote local knowledge, as well as facilitate sharing and improving social interaction for marginalised populations such as persons with disabilities [16]. Though not specific to mobile technology studies in China have shown internet connection significantly reduces social barriers for disabled people [17], and others in Peru, Jordan and India have shown technology use can improve social and economic aspirations [18]. Mobile phones have also been shown to help persons with disabilities in Jamaica stay informed, meet their emotional needs and interact with their peers [19]. Examples of mobile phone being used to engage people with disability in creating entertainment also exist such as the Cine para Todos (Cinema for Everyone) smart film festival where persons with disability were encouraged to make short films on their mobile phones and compete for a financial prize [5].

\section{B. Impact of access to mobile phones}

When people had access to a mobile phone, they felt independent and empowered. This in turn allowed people to overcome social and physical barriers as well as discrimination and to gain confidence and respect. A key factor in this independence was the feeling of safety increased by having 
immediate access to a mobile phone in case of any negative event. Another foundational aspect was access to reliable and trusted transport for both social and livelihood related purposes. This mitigates the challenges of poor infrastructure, lack of public transport options and perceptions of increased vulnerability to criminal acts of persons with disabilities.

However, this independence was not felt by all people equally and was affected by the social context of use. This is in keeping with thinking expressed by Holloway in her framework for assessing Disability Interaction [20] and the framework of Human Infrastructure [21] Mobile phone use is known to be mediated within low resource settings and (e.g. [14]). Socioeconomic factors as well as societal norms can result in mediated access to a mobile phone by surrogate users [21] and this was confirmed in our study with women in particular only having access to a mobile phone through a family member. This reflects the wider experience of many in Kenya and Bangladesh who do not own their phone as relatives tend to control what they do and limit time and access with the phone [8].

Other barriers include lack of digital literacy and attitudes of family who are reluctant to provide mobile phones to relatives with disabilities. In Bangladesh 19 percent of persons with disabilities reported not having access to a mobile phone [8]. Regardless of how a mobile phone was accessed when it was broken or stolen it resulted in social isolation and distress.

\section{Financial security}

The benefits of personal financial independence could also be seen where participants were empowered by having control of their finances through mobile phone banking. This ranged from being able to check balances and transactions privately to using mobile phone banking for business purposes. This was particularly important for people with visual impairment who could use text to voice to confidentially manage their accounts and transactions. This benefit was particularly clear for both basic mobile phones. These results are in keeping with the recent Kenyan study by [14].

Inclusive financial services have been shown to be vital to poverty reduction and in particular mobile phone banking apps have been shown to help persons with disabilities to manage their accounts and finances without depending on others [5], [22]. A GSMA study on the mobile disability gap found that 87 percent of persons with disability in Kenya have a registered mobile phone money account just below the 94 percent of nondisabled persons whereas in Bangladesh persons with disabilities were more likely to have an account at 25 percent compared to 14 percent of non-disabled persons [8]. Some mobile phone operators have added further advantages and protection for persons with disabilities to their mobile phone money services such as Safaricom in Kenya, who integrated Interactive Voice Response (IVR) in 2017 following a disability audit which found that visually impaired persons were being subjected to fraud. This resulted in a reduction in fraud [8]. This is a good example of how mainstream service providers can easily meet the needs of clients with disabilities.

\section{Access to opportunities}

In terms of empowerment through access to opportunities there were significant benefits of improved access to education and employment in both countries for participants across all selection criteria when mobile phones were accessible. From conducting personal research and advocacy on rights to engaging or teaching in formal education the value of mobile phones and services were made clear. This links to employment opportunities and improved livelihoods. Participants relied on mobile phones and services to be able to perform jobs in the public, private and third sector. Access to online banking, mobile phone money transactions and loans were shown to be transformative when the right support structures existed.

This shows, mobile technology opens opportunities and support persons with disabilities to include into mainstream activities. It supports the findings of recent GSMA research which has shown a strong correlation between disability, education, employment and income level in Kenya and Bangladesh. The study noted that disability is both a cause and outcome of poverty noting lower access to both education and employment among persons with disabilities [8]. This finding adds further weight to the previous research that has shown [2], [23], [24] that poverty and disability are both a cause and consequence of one another,

ICT has been shown to enable and empower persons with disability to engage in many forms of work and mobile phone technology and connectivity has further increased this potential. Improved communication through mobile phone instant chat, real time text displays and improved remote working have also contributed to this. There is also evidence that over the last 10 years mobile technology has become increasingly important to micro-entrepreneurs in particular those with disabilities. Other studies have shown that internet access act as an equalizer of opportunities for employment by improving independent work and outputs [5]. These trends are supported by the findings of this study.

\section{LIMITATIONS AND FUTURE WORK}

Participants expressed satisfaction with the photovoice approach as they felt connected, respected and were able to learn and share experiences. People with the lowest level of education in the most vulnerable circumstances took longer to grasp the concept of how they could use the technology to capture experiences. This made some stories more difficult to tell than others. During fieldwork, the research team faced challenges related to transport (distance, road condition, weather) which limited the possibility to reach out to a more diverse sample. Future studies would benefit from wider sample groups and a longer period for participants to have recording devices.

There is scope to increase sample size, duration of the information capture period and analysis of the impact on participants day-to-day lives including further exploration of the potential of basic, feature and smart phones. Investment in better use of basic and feature phones could have a significant impact on the most vulnerable who do not have access to or choose not to use smartphones due to their specific needs or economic circumstances. 


\section{CONCLUSION}

Our study details the stories of 16 persons with disabilities across two countries. We show that mobile phones within this context increase: 1) social connection through support groups, friends, family and entertainment; 2) Independence including improved access to appropriate transport, safety, financial services and healthcare (SDG3) and 3) Access to oopportunities for education (SDG4) and livelihoods (SDG8).

All participants noted significant benefits to having access to mobile phones and services both for themselves and other persons with disabilities. These benefits were found whether participants were using basic phones, feature phones or smartphones. Smartphones had some significant advantages as they were accessible and adaptive to users' needs but required a higher level of income and digital skills to use. Therefore, many people chose to use more basic phones due to ease of use.

In some instances, mobile phone use was via an intermediatory and this limited independence. Notwithstanding these cases of limited independence, the mobile phone was found to be liberating to all persons with disability within this study.

\section{ACKNOWLEDGMENT}

The present study was funded by the Global Disability Innovation Fund. The study was conducted by the GSMA, a trade association that represents over 750 mobile operator and digital players globally. Through the "Mobile for Development" (M4D) programme, the GSMA generates insights and engages with mobile operators and digital players to drive innovations in digital technologies to reduce global inequalities. The GSMA Assistive Tech programme is funded by the Department for International Development in the UK.

\section{REFERENCES}

[1] World Health Organization, 'World Report on Disability', 2011. [Online]. Available: http://www.who.int/disabilities/world_report/2011/report.pdf.

[2] C. Holloway, V. Austin, G. Barbareschi, and F. Ramos, 'Scoping Research Report on Assistive Technology', On the road for universal assistive technology coverage. Prepared by the GDI Hub \& partners for the UK Department for International Development. Global Disability Innvoation Hub, 2018.

[3] GSMA, 'The Mobile Economy', 2019. [Online]. Available: https://www.gsmaintelligence.com/research/?file=b9a6e6202ee1d5f787c febb95d3639c5\&download.

[4] G. Barbareschi, C. Aranda Jan, M. Nique, F. Ramos Barajas, and C. Holloway, 'Mobile Phones as Assistive Technologies: Gaps and Opportunities', 2019.

[5] S. Thompson, 'Mobile Technology and Inclusion of Persons with Disabilities', May 2018, Accessed: May 14, 2020. [Online]. Available: https://opendocs.ids.ac.uk/opendocs/handle/20.500.12413/13834.

[6] Enable Ireland, 'Assistive Technology for People with Disabilities and Older People', Nov. 2016. [Online]. Available: https://www.enableireland.ie/sites/default/files/publication/AT\%20Paper $\% 20$ final\%20version.pdf.
[7] L. Hakobyan, J. Lumsden, D. O'Sullivan, and H. Bartlett, 'Mobile assistive technologies for the visually impaired', Survey of Ophthalmology, vol. 58, no. 6, pp. 513-528, Nov. 2013, doi: 10.1016/j.survophthal.2012.10.004.

[8] GSMA, 'Understanding the mobile disability gap', 2019. [Online]. Available: https://www.gsma.com/mobilefordevelopment/wpcontent/uploads/2019/12/GSMA Understanding-the-mobile-disabilitygap_116pg_Accessible.pdf.

[9] C. L. Bennett and D. K. Rosner, 'The Promise of Empathy: Design, Disability, and Knowing the" Other"', in Proceedings of the 2019 CHI Conference on Human Factors in Computing Systems, 2019, pp. 1-13.

[10] C. A. Sutton-Brown, 'Photovoice: A Methodological Guide', Photography and Culture, vol. 7, no. 2, pp. 169-185, Jul. 2014, doi: $10.2752 / 175145214 X 13999922103165$.

[11] J. Falconer, Photovoice Participatory-Action Research Design and Adaptations for Adverse Fieldwork Conditions. 1 Oliver's Yard, 55 City Road, London EC1Y 1SP United Kingdom: SAGE Publications, Ltd., 2014.

[12] J. I. Charlton, Nothing About Us Without Us: Disability Oppression and Empowerment, 1st ed. University of California Press, 1998.

[13] V. Braun and V. Clarke, 'Using thematic analysis in psychology', Qualitative Research in Psychology, vol. 3, no. 2, pp. 77-101, Jan. 2006, doi: 10.1191/1478088706qp063oa.

[14] G. Barbareschi et al., 'The Social Network: How People with Visual Impairment use Mobile Phones in Kibera, Kenya', in Proceedings of the 2020 CHI Conference on Human Factors in Computing Systems, Honolulu, HI, USA, Apr. 2020, pp. 1-15, doi: 10.1145/3313831.3376658.

[15] S. P. Wyche and L. L. Murphy, "'Dead China-make" phones off the grid: investigating and designing for mobile phone use in rural Africa', in Proceedings of the Designing Interactive Systems Conference, Newcastle Upon Tyne, United Kingdom, Jun. 2012, pp. 186-195, doi: 10.1145/2317956.2317985.

[16] T. Barlott, K. Adams, and A. Cook, 'Increasing participation in the information society by people with disabilities and their families in lowerincome countries using mainstream technologies', Univ Access Inf Soc, vol. 15, no. 2, pp. 189-198, Jun. 2016, doi: 10.1007/s10209-015-0418-z.

[17] B. Guo *, J. C. Bricout, and J. Huang, 'A common open space or a digital divide? A social model perspective on the online disability community in China', Disability \& Society, vol. 20, no. 1, pp. 49-66, Jan. 2005, doi: 10.1080/0968759042000283638.

[18] J. Pal, T. Ammari, R. Mahalingam, A. M. H. Alfaro, and M. Lakshmanan, 'Marginality, aspiration and accessibility in ICTD', in Proceedings of the Sixth International Conference on Information and Communication Technologies and Development: Full Papers - Volume 1, Cape Town, South Africa, Dec. 2013, pp. 68-78, doi: 10.1145/2516604.2516623.

[19] H. S. Dunn, 'Wha'a Gwaan?: research report on a qualitative study of mobile telephony and poverty in Jamaica.', 2016.

[20] C. Holloway, 'Disability Interaction (DIX): A Manifesto', Interactions, vol. 26, no. 2, pp. 44-49, Feb. 2019, doi: 10.1145/3310322.

[21] N. Sambasivan and T. Smyth, 'The human infrastructure of ICTD', in Proceedings of the 4th ACM/IEEE international conference on information and communication technologies and development, 2010, pp. $1-9$.

[22] D. S. Raja, 'Bridging the disability divide through digital technologies', Background paper for the World Development report, 2016.

[23] N. Groce and M. Kett, 'The disability and development gap', Leonard Cheshire Disability and Inclusive Development Centre Working Paper Series, no. 21, 2013.

[24] L. M. Banks, H. Kuper, and S. Polack, 'Poverty and disability in low-and middle-income countries: A systematic review', PloS one, vol. 12, no. 12, 2017. 